\title{
Malocclusion in Elementary School Children in Beirut: Severity and Related Social/Behavioral Factors
}

\author{
Antoine Hanna, ${ }^{1}$ Monique Chaaya, ${ }^{2}$ Celine Moukarzel, ${ }^{3}$ Khalil El Asmar, \\ Miran Jaffa, ${ }^{2}$ and Joseph G. Ghafari ${ }^{1}$ \\ ${ }^{1}$ Division of Orthodontics and Dentofacial Orthopedics, Department of Otolaryngology/Head and Neck Surgery, \\ American University of Beirut Medical Center, Beirut, Lebanon \\ ${ }^{2}$ Department of Epidemiology and Population Health, Faculty of Health Sciences, American University of Beirut, Beirut, Lebanon \\ ${ }^{3}$ Private Practice, Beirut, Lebanon \\ Correspondence should be addressed to Monique Chaaya; mchaaya@aub.edu.lb
}

Received 7 August 2014; Accepted 26 November 2014

Academic Editor: James K. Hartsfield

Copyright (C) 2015 Antoine Hanna et al. This is an open access article distributed under the Creative Commons Attribution License, which permits unrestricted use, distribution, and reproduction in any medium, provided the original work is properly cited.

\begin{abstract}
Aim. To assess severity of malocclusion in Lebanese elementary school children and the relationship between components of malocclusion and sociodemographic and behavioral factors. Methods. Dental screening was performed on 655 school children aged 6-11 from 2 public (PB) and 5 private (PV) schools in Beirut. A calibrated examiner recorded occlusion, overjet, overbite, posterior crossbite, midline diastema, and crowding. Another examiner determined the DMFT (Decayed/Missing/Filled Teeth) score. A questionnaire filled by the parents provided data on sociodemographic and behavioral factors. Multinomial, binomial, and multiple linear regressions tested the association of these factors with occlusal indices. Results. Malocclusion was more severe in PB students. Age and sucking habit were associated with various components of malocclusion. Crowding was more prevalent among males and significantly associated with the DMFT score. Income and educational level were significantly higher $(P<0.05)$ in PV pupils and deleterious habits were more frequent in PB children. Conclusions. Children of lower socioeconomic background had more severe malocclusions and poorer general dental health. Compared to Western and WHO norms, the findings prompt health policy suggestions to improve dental care of particularly public school children through regular screenings in schools, prevention methods when applicable, and cost effective practices through public and private enabling agencies.
\end{abstract}

\section{Introduction}

Malocclusion is defined as any deviation from the norm of the arrangement of the teeth and occurs commonly among various populations [1,2]. While considered nonlife threatening, malocclusion may cause altered functions (mastication, speech) and poor dentofacial esthetics that reduce the quality of life of affected subjects including social and functional limitations [3]. Malocclusion has also been associated with the development of periodontal disease, albeit not a direct etiology [4].

The assessment of malocclusion has not been uniform. Relatively subjective weights are assigned to the components of malocclusions in different rating systems [5], eventually leading to variable reporting of orthodontic treatment need.
The corresponding scoring indices have been used by governmental and insurance agencies to determine eligibility and/or amount of treatment coverage.

Prevalence of malocclusion in the deciduous (primary), intermediate, and permanent dentitions varied widely across studies and countries because of population differences (races/ethnicity), sample sizes, age range of the surveyed children, and methods of measurement [6-10]. Yet, fewer differences were found in classification of malocclusion because of more standardized norms of the relationship between maxillary and mandibular molars (molar occlusion) or the overjet (horizontal overbite) between upper and lower incisors. In general, these relations are well correlated [11].

In Western Studies (mainly American) spanning over 50 years, the majority of malocclusions in Caucasian children 
exhibit Class I malocclusion (nearly 75\%), with closer to normal relations between the posterior teeth, followed by Class II malocclusion (tendency to increased overjet, nearly 20\%), then Class III (anterior underbite-less than 5\%) [2]. Surveys of Brazilian children indicated lower proportions but still a majority of Class I malocclusion and higher percentages of Class II and Class III problems [12, 13].

Fewer studies are available on prevalence of malocclusion in the Middle East and Northern Africa region, but the same pattern of malocclusion as in Western countries seemingly holds, although in varied proportions. The majority of malocclusions in Middle Eastern countries related to Class I in children, adolescents, or young adults, followed by Classes II and III [14-18]. In some studies the components of the malocclusion were further qualified [14, 16-18].

Although scarce, studies that have directly related malocclusion and its severity to social status indicated that children with relatively poor lifestyle have higher orthodontic treatment need compared to their counterparts with wealthier lifestyle $[19,20]$. Social condition also can affect malocclusion indirectly. Underprivileged people are more exposed to risk factors that affect oral health: unhealthy diet, tobacco use, excessive consumption of alcohol, poor sanitation and polluted water, poor oral hygiene, and HIV infection [21]. Poor oral health leads to caries and early tooth loss, facilitating the development of malocclusion, hence greater need for orthodontic treatment $[22,23]$.

The available data on malocclusion in Lebanon only cover the age range of 9-15 years. Prevention of oral disease or dysmorphology is usually implemented at an earlier age, thus the importance of assessing the prevalence of malocclusion at younger ages (6-11 years). Relating malocclusion to social/behavioral factors in early childhood shall facilitate the prevention or decrease in severity of malocclusion, particularly in the presence of guidelines recommending intervention before the emergence of all permanent teeth (usually by age 12 years) [24].

Accordingly, our aim was to evaluate in prepubertal Lebanese students from presumably varied backgrounds, attending public and private schools, the prevalence of malocclusion and its relation to social and behavioral characteristics. Such information potentially helps public health workers to plan intervention programs and highlight the importance of early orthodontic screening.

\section{Material and Methods}

The investigation was a comparative cross-sectional study of elementary school children in grades 2 to 5 , aged 6-11 years, attending public and private schools in Beirut, Lebanon. The data were collected through an oral examination and a questionnaire sent to parents or guardians. The Institutional Review Board of the American University of Beirut and the Ethics committees of all participating institutions approved the study along with the pertinent consent forms secured by the parents and the assent provided by children.
2.1. Sample Size Calculation. A sample size of 721 was determined through the A Priori Sample Size Calculator for Multiple Regression [25] with an anticipated effect size (f2) of 0.02, a statistical power level of $0.8,7$ predictors, and a probability level of 0.05 . Accounting for probable missing data we inflated the sample size by 1.2; for nonresponse from the parents or the children we further inflated the size by 1.25 , whereby we sought to approach a number of nearly 1000 children.

2.2. Participants. Access to public schools was possible through a local nongovernmental organization (NGO, "Ajialouna") in Beirut, dedicated to improve life standards through various projects such as school health, health education programs, orphan sponsorship and other commitments. From a total of 30 public schools, two schools were chosen based on a timetable provided by the NGO indicating the readiness of schools for the survey and prior consent from parents that cleared our conduct of oral examination on 530 children. However, only 325 (61.3\%) of these students were recruited, because the parents of the remaining 205 children did not consent to participate in the survey. The findings of the oral examinations of these pupils were used only to determine potential differences with the consenting participants.

Private schools were selected based on location (Beirut and suburbs) and willingness to participate. From 12 contacted schools, five agreed to partake in the study, encompassing 1119 children from average to high socioeconomic status. The parents/guardians of 333 children (29.76\%) agreed to enroll their child and answered the survey. Excluding 3 subjects with prior or current interceptive orthodontic treatment, the final number was 330 . The comparatively low response rate was probably related to the prior dental screening at the start of the school year in some of the schools, or to a more regular follow-up by a private dentist. The total sample size of both private and public schools was 655 .

2.3. Instruments. The components of the US National Health and Nutrition Estimates Survey (NHANES) malocclusion assessment model were used. They included spacing within the arch (crowding, midline diastema) and relations between maxillary and mandibular teeth in the 3 planes of space: sagittal (relations between anterior teeth: overjet or anterior crossbite; relationship between the first permanent molars (Class I, II, or III)), vertical (overbite or open bite), and transversal (posterior crossbite). The study deviated from the NHANES gauge in 2 aspects.

(1) A more complete description of the malocclusion was added by dividing the molar occlusion into 5 categories based on half-cusp deviation and recording the overbite not only in millimeters but also as percentage of overlap of the mandibular incisors by the maxillary incisors.

(2) The maxillary irregularity index was discarded because the sample age bracket (6-11 years) was lower than the NHANES range (8-11 years), precluding the examination of a large number of children with nonerupted maxillary lateral incisors. Given a high correlation between the maxillary and mandibular irregularity scores [2], the latter increasing more from 
childhood to adulthood, we projected the mandibular score to properly represent the presence and severity of crowding. Additional findings worth reporting were noted separately (missing and supernumerary teeth, impeded eruption of teeth).

Outcome was classified into quantitative measurements (number of teeth in crossbite and percentage of overbite), nominal measurements (molar and canine occlusion), or an ordinal variable reflecting severity (crowding, overjet, and overbite).

The DMFT (Decayed/Missing/Filled Teeth) score and the plaque index (a measure of hygiene) were recorded for each child to be analyzed in a different paper.

The questionnaire addressed to parents included 41 questions in the following categories:

(a) sociodemographic background of child and parents (family status and educational background of the respondent, family monthly income, and child's birth order),

(b) general health status of the child (presence/absence of chronic disease, child's breathing mode, and smoking status of the mother during pregnancy),

(c) sucking habits of the child (digit or other object, duration, and intensity of sucking),

(d) feeding methods of the child (feeding mode of child during infancy, consumption of detrimental foods),

(e) oral health behaviors (brushing habits, visits to the dentist),

(f) perception of parents towards their child's oral health (malocclusion and decays).

2.4. Procedure. Calibration studies preceded the in-field examinations. The dental examination comprised two distinct parts: the collection of occlusal data (investigator $\mathrm{AH}$ ); the determination of the DMFT and plaque scores (investigator $\mathrm{CM}$ ). The dental instruments used were noninvasive mouth mirrors, probes, and periodontal probes (ZFA043\#11, Co), available in disposable packages. The screenings were performed according to WHO standards [26].

A document was sent with the children to their parents, including all pertinent information regarding the study, the IRB-approved questionnaire, and consent form. When the child was found to require treatment, a note was sent to the parents or legal guardian(s). Essential information contacts of nearby specialized dental centers with reasonable treatment cost were provided to the parents when the child was not being followed up by a dentist.

2.5. Data Analysis. Frequency distributions for all variables helped assess variability and data regrouping. Outcome indicators were chosen to represent each plane of space: overjet, overbite, and posterior crossbite. Bivariate associations gauged how different malocclusion components vary relative to selected characteristics, through chi-square tests or independent sample $t$-tests between each dependent variable and the study covariates, depending on the nature of the variables.

Multivariate analysis was performed using the generalized estimated equations (GEEs), to estimate coefficients and odds ratios by fitting regression models with continuous (overjet in $\mathrm{mm}$ ) and binary (presence/absence of posterior crossbite) outcomes adjusted for clustering effect. As GEE does not model multinomial outcome variables, generalized linear models (GLM) were used to estimate relative risk ratios (RRR) by fitting multinomial logistic regression models for outcome variables having more than 2 categories (overjet severity, overbite severity, and irregularity score severity). Clustering effect was adjusted for in the variance-covariance matrix structure and robust standard errors were reported. The multinomial regression was used instead of the ordinal logistic regression because the proportional odds assumption did not hold.

All covariates statistically associated with outcome variables at the bivariate level of $P<0.2$ were included in the multivariate analysis. For all parameters, 95\% CI and twosided $P$ values were reported. Statistical significance was set at $P<0.05$. All analyses were completed in Stata SE 10.1.

\section{Results}

3.1. Sociobehavioral Characteristics. Mean age was not significantly different between private schools [PV] (8.57 \pm 1.31 yrs. $)$ and public schools $[\mathrm{PB}](8.49 \pm 1.59$ yrs. $)$ children. The proportion of girls was slightly higher in PV (52.8\%) than in PB (46.2\%) schools, but the difference was not statistically significant.

Statistically significant differences were found between both groups for family income and educational level of parents, the higher levels detected among parents of PVS children (Table 1). Regarding behavioral factors, the proportion of children whose mothers smoked during pregnancy was nearly 3 times higher among PB (20.4\%) compared to PV schools. Reported sucking habits were also higher for PB children (Table 2).

3.2. Dental Measures. To facilitate the communication of a large set of data, only malocclusion parameters (by type of school) with statistically significant differences between PB and PV children are displayed in Table 3. The largest proportions of PB and PV children had Class I (normal) occlusion. The type of occlusion classified by molar relations (Class I, II, or III) was not statistically significantly different between school groups; however, when occlusion was stratified based on overjet severity the differences were significant (Table 3). PB children had statistically significantly greater mean and higher percentage of OJ compared with PV children. Anterior crossbite (reverse overjet) was statistically significantly different between the groups in Class III malocclusions. Midline diastema was more prevalent in public compared to private schools.

Vertical measures (open bite, overbite) were not statistically significantly different between school groups; however, transverse abnormalities (posterior crossbite and midline 
TABLE 1: Sociodemographic variables.

\begin{tabular}{|c|c|c|c|}
\hline \multirow[b]{2}{*}{ Characteristics } & \multicolumn{2}{|c|}{ School type } & \multirow[b]{2}{*}{$P$ value } \\
\hline & $\begin{array}{c}\text { Public } \\
(n=325)\end{array}$ & $\begin{array}{c}\text { Private } \\
(n=330)\end{array}$ & \\
\hline \multirow[t]{2}{*}{ Age (years) } & $8.49 \pm 1.59$ & $8.57 \pm 1.31$ & NS \\
\hline & $\%$ & $\%$ & \\
\hline \multicolumn{4}{|l|}{ Gender } \\
\hline Males & 52.8 & 46.2 & \multirow{2}{*}{ NS } \\
\hline Females & 47.2 & 53.8 & \\
\hline \multicolumn{4}{|l|}{ Family income (LL) } \\
\hline$<500,000$ & 33.6 & 1.4 & \multirow{4}{*}{0.000} \\
\hline $500,000-999,999$ & 49.4 & 14.2 & \\
\hline $1,000,000-3,000,000$ & 15.1 & 57.6 & \\
\hline$>3,000,000$ & 2.1 & 26.4 & \\
\hline \multicolumn{4}{|l|}{ Education of informant } \\
\hline $\begin{array}{l}\text { Low (illiterate-primary } \\
\text {-elementary) }\end{array}$ & 45.4 & 7.7 & \multirow{3}{*}{0.000} \\
\hline $\begin{array}{l}\text { Average } \\
\text { (secondary-intermediate) }\end{array}$ & 44.1 & 20.0 & \\
\hline High (college/university) & 10.5 & 72.4 & \\
\hline
\end{tabular}

diastema) were more frequent in $\mathrm{PB}$. The overall DMFT scored a mean of $7.30 \pm 3.98$ in $\mathrm{PB}$ children compared with a mean of $3.50 \pm 3.41$ in PV schools $(P<0.0001)$. The number of decayed teeth was significantly higher in $\mathrm{PB}$ compared to PV $(P \leq 0.0001)$ schools, with means of $5.67 \pm 3.81$ and $1.48 \pm 2.19$, respectively.

\subsection{Associations among Variables}

3.3.1. Bivariate Associations. Only statistically significant associations are displayed in Table 4. Overjet was statistically significantly associated with age (6-7 years when permanent incisors and first molars erupt, and 8-11 years prior and during the eruption of permanent canines and premolars) and DMFT score. DMFT scores were significantly higher in children with more severe overjet. Overbite was significantly associated with age and plaque index. A higher proportion of older children had severe overbite compared to younger ones. The mean plaque index was greater in subjects with deeper bite. The post hoc test showed that the statistically significant difference existed between the subjects with moderate and deep bite $(P=0.043)$. Children with sucking habits were almost twice more likely to have at least one tooth in posterior crossbite compared to those with no sucking habit. None of the occlusal variables were associated with the amount or severity of the irregularity index.

3.3.2. Multivariate Analysis. The clustering by school did not appear to have any effect on the regression outcome of the overjet, overbite, and irregularity index. However, for the posterior crossbite, age only became significant following adjustment for clustering.

Adjusting for gender, school type, educational level, sucking duration, DMFT score, and plaque index, the results
TABLE 2: Health and behavioral characteristics of child and mother.

\begin{tabular}{lccc}
\hline \multicolumn{3}{c}{ School type } & \\
Characteristics & Public & Private & $P$ value \\
& $(n=325)$ & $(n=330)$ & \\
& $\%$ & $\%$ & \\
\hline Chronic diseases & & & \\
$\quad$ Yes & 13.4 & 9.1 & NS \\
$\quad$ No & 86.6 & 90.9 & \\
Mouth breathing & & & \\
$\quad$ Yes & 9.8 & 7.7 & NS \\
$\quad$ No & 90.2 & 92.3 & \\
Sucking habits & & & \\
$\quad$ Yes & 19.56 & 14.9 & 0.030 \\
$\quad$ No & 80.43 & 85.1 & \\
Maternal smoking during & 20.4 & 7.0 & 0.000 \\
pregnancy (cigarettes) & & & \\
Feeding method & & 31.0 & \\
$\quad$ Breast & 53.3 & 24.2 & NS \\
Bottle & 22.7 & 44.8 & \\
Both & 24.0 & &
\end{tabular}

TABLE 3: Percentage distribution of malocclusion characteristics in public and private school children.

\begin{tabular}{lccc}
\hline \multirow{2}{*}{ Measures } & \multicolumn{2}{c}{ School type } & \\
& $\begin{array}{c}\text { Public } \\
(n=325)\end{array}$ & $\begin{array}{c}\text { Private } \\
(n=330)\end{array}$ & $P$ value $^{*}$ \\
\hline Overjet (\%) & & & \\
1-2 [ideal] & 27.4 & 36.3 & \\
3-4 [mild] & 46.2 & 45.0 & 0.022 \\
$\quad>4$ [mod-sev] & 26.4 & 18.7 & \\
Mean OJ (mm) & $3.71 \pm 1.77$ & $3.41 \pm 1.7$ & 0.032 \\
Anterior crossbite (\%) & & & \\
$\quad$ [mild] & 5.23 & 0.9 & \\
$\quad-1$ to -2 [moderate] & 5.5 & 6.6 & 0.008 \\
$\quad-3$ to -4 [severe] & 0.3 & 0.9 & \\
$\quad<-4$ [extreme] & 0.0 & 0.0 & \\
Occlusion** (\%) & & & \\
I & 72.93 & 77.57 & \\
II & 23.69 & 16.96 & 0.002 \\
III & 3.38 & 5.45 & \\
Midline diastema $(>2 \mathrm{~mm})$ & 16.1 & 10.5 & 0.036 \\
\hline
\end{tabular}

${ }^{*}$ Chi-square.

${ }^{* *} \mathrm{Cl}$ I, Cl II, and Cl III classified based on OJ (ideal: 1-4; >4: Cl II; reverse overjet: $\mathrm{Cl}$ III).

indicate that a subject older than 8 years is at higher risk to have a mild rather than an ideal overjet (RRR: 1.35; 95\% CI: 1.04-1.28; Table 5). Children with higher plaque index were at a lower risk of having a severe overjet (RRR: 0.93 ; $95 \%$ CI: $0.88-0.98)$. 
TABLE 4: Associations in percentage between components of malocclusion and other variables.

\begin{tabular}{|c|c|c|c|c|}
\hline & Associations & & & $P$ value \\
\hline Overjet & 1-2 [ideal] & 3-4 [mild] & $4<$ [mod-sev $]$ & \\
\hline \multicolumn{5}{|l|}{ Age } \\
\hline$(6-7)$ & 38.6 & 41.9 & 19.5 & \multirow{2}{*}{0.033} \\
\hline$(8-11)$ & 28.2 & 48.0 & 23.8 & \\
\hline DMFT & $4.79 \pm 3.98$ & $5.36 \pm 4.24$ & $6.18 \pm 4.12$ & 0.030 \\
\hline Overbite & $0-2$ [ideal] & 3-4 [moderate] & $5<$ [mod-sev $]$ & \\
\hline \multicolumn{5}{|l|}{ Age } \\
\hline$(6-7)$ & 63.9 & 24.4 & 11.8 & \multirow{2}{*}{0.033} \\
\hline$(8-11)$ & 48.7 & 27.4 & 23.8 & \\
\hline Plaque index (PI) & $1.27 \pm 0.21$ & $1.24 \pm 0.16$ & $1.30 \pm 0.22$ & 0.049 \\
\hline Posterior crossbite & Present & & & \\
\hline \multicolumn{5}{|l|}{ Sucking habits } \\
\hline Present & 75.8 & \multicolumn{2}{|c|}{24.2} & \multirow[t]{2}{*}{0.005} \\
\hline Not present & 86.9 & \multicolumn{2}{|c|}{13.1} & \\
\hline
\end{tabular}

When using the overjet as a continuous outcome and adjusting for the same covariates employed in the multinomial model, the regression model resulted in a positive correlation between age and overjet ( $\beta$ : 0.14 ; 95\% CI: $0.046-$ 0.249; Table 5). PV students were more likely to have a lower overjet than those attending public school $(\beta$ : $-0.10 ; 95 \%$ CI: $-0.185 ;-0.026)$. Family income was positively associated with overjet, children of lower income families $(<500,000 \mathrm{LL})$ exhibiting a greater likelihood for increased overjet.

Subjects 8-11 years of age were at a higher risk of having mild (RRR: $1.71 ; 95 \%$ CI: $1.21 ; 2.39$ ) and moderate to severe (RRR: 2.23; 95\% CI: 1.03; 4.83) overbite (Table 5). Also, children with increased sucking habit duration (RRR: 0.98; 95\% CI: 0.97; 0.99) and higher DMFT score (RRR: 0.93; 95\% $\mathrm{CI}: 0.86 ; 0.99)$ were at a lower risk of reporting moderate to severe overbite.

The odds of having posterior crossbite in 8-11-year old children and those with increased sucking habit duration were 1.29 (95\% CI: $1.18 ; 1.39)$ and 1.01 (95\% CI: 1.01; 1.18), respectively. Subjects with mouth breathing habit were more likely to have a mild irregularity index (RRR: 2.61; 95\% CI: $1.99 ; 3.42)$. A higher risk of moderate to severe irregularity index was determined for male subjects (RRR: 1.69; 95\% CI: $1.36 ; 2.1$ ) and children with higher DMFT score (RRR: 1.04; 95\% CI: 1.03 ; 1.06).

\section{Discussion}

This study addressed for the first time the magnitude and severity of malocclusion conditions in preadolescent Lebanese children, a comparison between public and private school children, and the association of social and behavioral factors with a wide range of malocclusion features.

4.1. Malocclusion. In addition to high malocclusion severity in all children, this study disclosed varying magnitudes of severity between the two school groups, depending on the malocclusion variable. The most prevalent variable was the overjet, which occurred in at least $20 \%$ of children. However, the statistically significant difference between OJ in PB (3.71 \pm $1.77 \mathrm{~mm})$ and PV $(3.41 \pm 1.70 \mathrm{~mm})$ arguably may not be clinically significant.

For a more universal perspective, we compared our findings with the published data from the NHANES III survey, carried out between 1988 and 1999 on nearly 7000 individuals from different racial/ethnic and age groups [2]. Malocclusion in the NHANES was stratified on the overjet. Our findings regarding molar occlusion are consistent with other studies of Caucasian children $[12,13]$. When malocclusion was classified on overjet, more similarities were found with the literature $[2,27]$ but the occlusion in public school children was most similar to the NHANES III data (Figure 1). Less Class II malocclusion and more Class I occlusions were found in the private schools (77.57\% Class I, $16.96 \%$ Class II) compared to both NHANES III (74.8\% Class I, 22.5\% Class I) and public school (72.93\% Class I, 23.69\% Class II) data.

In some patients, the relationship between maxillary and mandibular molars falls between the three classes of malocclusion. Accordingly, the overjet was used as a more practical but not perfect proxy in various studies [27, 28]. In our sample, more than 9 of 10 subjects with an overjet greater than $6 \mathrm{~mm}$ had a Class II molar relationship, a finding consistent with other studies [28].

In other aspects of malocclusion, the following comparisons emerge (Figure 1).

(a) The prevalence of overjet and overbite in the moderate to severe range is greater in the NHANES III survey than in the PV schools, but less than in the PB schools. This disparity may relate to the wider range or lack of differentiation of socioeconomic backgrounds in the US survey compared to the differentiated socioeconomic levels of the PV and PB children in this study. 
TABLE 5: Multivariate analysis of associations between categories of malocclusion and other variables.

\begin{tabular}{|c|c|c|c|c|}
\hline \multicolumn{5}{|c|}{ Overjet $^{*}$} \\
\hline Variable & RRR & Robust SE & $95 \% \mathrm{CI}$ & $P$ value \\
\hline \multicolumn{5}{|l|}{ Mild } \\
\hline Age (6-7 versus 8-11) & 1.35 & 0.16 & {$[1.067 ; 1.71]$} & 0.013 \\
\hline \multicolumn{5}{|l|}{ Moderate to severe } \\
\hline Plaque index & 0.93 & 0.024 & {$[0.888 ; 0.983]$} & 0.009 \\
\hline \multicolumn{5}{|c|}{ Overjet (continuous measurement) } \\
\hline Variable & $\beta$ & Semi-Robust SE & $95 \% \mathrm{CI}$ & $P$ value \\
\hline Age & 1.15 & 0.051 & {$[1.04 ; 1.28]$} & 0.004 \\
\hline School type & 0.9 & 0.04 & {$[0.831 ; 0.974]$} & 0.009 \\
\hline \multicolumn{5}{|l|}{ Family income ${ }^{* *}$} \\
\hline $500,000-999,999$ & 1.229 & 0.070 & {$[1.07 ; 1.41]$} & 0.003 \\
\hline $1,000,000-3,000,000$ & 1.328 & 0.044 & {$[1.209 ; 1.447]$} & 0.000 \\
\hline$>3,000,000$ & 1.205 & 0.123 & {$[0.94 ; 1.535]$} & 0.131 \\
\hline \multicolumn{5}{|c|}{ Overbite $^{*}$} \\
\hline Variable & RRR & Robust SE & $95 \% \mathrm{CI}$ & $P$ value \\
\hline \multicolumn{5}{|l|}{ Mild } \\
\hline Age (6-7 versus 8-11) & 1.709 & 0.294 & {$[1.21 ; 2.39]$} & 0.002 \\
\hline \multicolumn{5}{|l|}{ Moderate to severe } \\
\hline Age (6-7 versus 8-11) & 2.238 & 0.880 & {$[1.035 ; 4.83]$} & 0.040 \\
\hline Sucking duration & 0.983 & 0.004 & {$[0.97 ; 0.992]$} & 0.000 \\
\hline DMFT & 0.930 & 0.033 & {$[0.866 ; 0.999]$} & 0.048 \\
\hline \multicolumn{5}{|c|}{ Posterior crossbite } \\
\hline Variable & OR & Semi-Robust SE & $95 \%$ CI & $P$ value \\
\hline Age (6-7 versus $8-11)$ & 1.29 & 0.041 & {$[1.188 ; 1.39]$} & 0.000 \\
\hline Sucking duration & 1.014 & 0.001 & {$[1.011 ; 1.185]$} & 0.000 \\
\hline \multicolumn{5}{|c|}{ Irregularity index ${ }^{*}$} \\
\hline Variable & RRR & Robust SE & $95 \%$ CI & $P$ value \\
\hline \multicolumn{5}{|l|}{ Mild } \\
\hline Mouth breathing & 2.612 & 0.362 & {$[1.99 ; 3.428]$} & 0.000 \\
\hline \multicolumn{5}{|l|}{ Moderate to severe } \\
\hline Gender & 1.692 & 0.189 & {$[1.359 ; 2.1]$} & 0.000 \\
\hline DMFT & 1.049 & 0.0082 & {$[1.033 ; 1.065]$} & 0.000 \\
\hline
\end{tabular}

* Ideal category as base outcome.

$*^{*}<500.000$ as base outcome.

$\beta$-slope of regression; OR: odds ratio; RRR: relative risk ratio.

(b) A higher prevalence of open bite, posterior crossbite, and crowding in Lebanese school children compared to the NHANES III. The difference might relate to the higher prevalence/severity of sucking habits in our sample.

(c) A lower irregularity index in the NHANES III than in both groups. The higher incidence in males is similar to the NHANES III, while being inconsistent with other studies in which no differences [1] or higher female prevalence $[29,30]$ was found.

The epidemiology of malocclusion is significant because of multilevel impacts.

(a) Personal image: malocclusion may influence selfconcept. Our findings on crowding (OR:5.359) and crossbite (OR:6.153) were reported by other investigators as risk factors for "global self-concept" (includes six domain-specific scales: social, competence, affect, academic, family, and physical) [31].

(b) Individual health: Our observations on anterior crossbite [underbite] $(\mathrm{OR}=4.016)$ and molar relationship $(\mathrm{OR}=1.661)$ match other findings that disclosed these characteristics as risk indicators for speech and chewing capabilities, respectively [32].

(c) Quality of life in general: patients with severe malocclusion scored poorer oral health-related quality of life (OHRQoL) than patients with less critical treatment need [33]. Also, orthodontic intervention would enhance some aspects of OHRQoL. More specific to the age bracket we investigated (6-11 years), early orthodontic intervention is beneficial because 


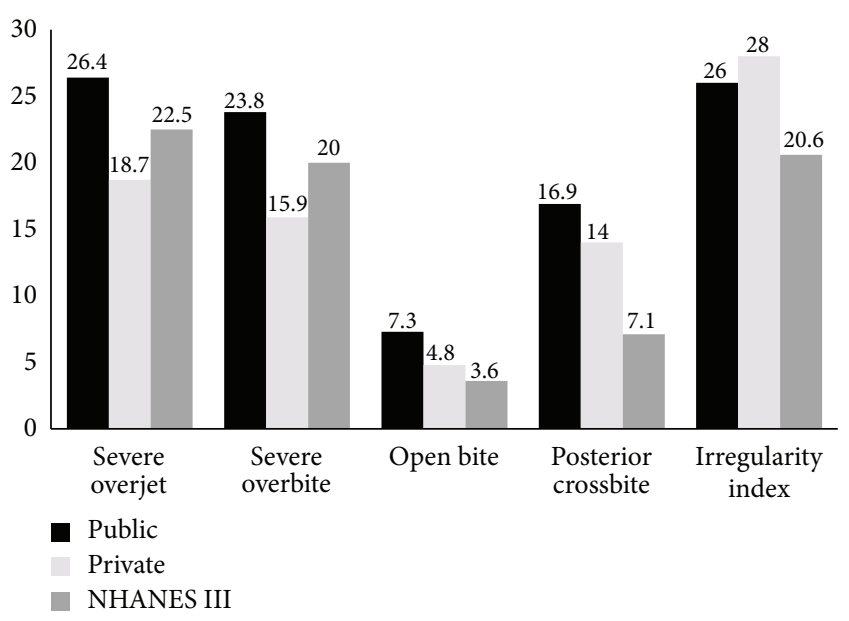

FIGURE 1: Percent distribution of students aged 8-11 by malocclusion characteristics and type of school (public and private) compared with the NHANES III findings.

younger children have high self-esteem and bodyimage and expect orthodontics to improve their lives [33].

4.2. Associations. Associations are listed in 2 categories, those first found in this study and those corroborated in other studies.

\subsubsection{New/Different Findings}

(a) Overbite was negatively associated with DMFT score. This finding might be partially explained by the association between mouth breathing (usually associated with open bite [34]) and increased risk of caries, through the reduction of the salivary flow that helps protect the teeth against decay [35].

(b) The multivariate analysis suggests that being in a private school is "protective" against increased overjet. The increased overjet might be linked to the environment in which the students live where some conditions (possibly higher rate of upper respiratory tract infections or pollution) enhance mouth breathing. Further research is needed to determine reasons for the differences.

4.2.2. Findings Supported in the Literature. Consider the following:

(a) correspondence of family income and education [36],

(b) more prevalent sucking habits in PB children, possibly reflecting the reported increase in sucking habits of children feeling insecure, lonely, or stressed [37],

(c) higher proportion (3-fold) of mothers of PB children who smoked during pregnancy, concurring with prior conclusions that smoking during pregnancy is negatively correlated with educational level and socioeconomic status $[38,39]$, (d) the association between overbite and sucking duration $[40,41]$, possibly explained by the link of sucking habits with tongue thrust and abnormal swallowing pattern [42],

(e) positive associations between posterior crossbite and age and between crossbite and the presence (and duration) of a sucking habit [43],

(f) the association between irregularity of incisors and DMFT $[44,45]$. More caries may develop because of inappropriate brushing of the crowded incisors,

(g) the association between mouth breathing and increased irregularity score of the mandibular incisor [46]. Focused investigation is needed for definitive explanation.

Because all investigated children were past the primary dentition, comparisons are not possible with reports of association between sucking habits and increased overjet in this dentition $[47,48]$. However, it is plausible that the higher prevalence of severe OJ in public school children was related to higher prevalence and intensity of sucking duration at an earlier age.

4.3. Implications for School Health. The findings underscore the need to reduce social disparities in oral health among Lebanese city pupils. The inequality stems from living conditions and unequal access to proper dental awareness/education and care. Short- and long-term strategies are considered to remedy this problem.

4.3.1. Short-Term Recommendations. Regular annual dental screening is a public health service that should be generalized to all schools, not limited to mostly private and NGOsupported public schools, through the following:

(a) integrating orthodontic screening in the annual health evaluation, involving an orthodontist or trained dentist or dental hygienist, and basic screening tools. Several alternatives may be explored when funds are lacking: the assistance of civil NGO or charity organizations; volunteer dental examiners; coordination with orthodontic residency programs (possibly within a community service requirement for residency certification),

(b) the requirement by governmental health and educational agencies for all schools to institute an annual orthodontic/dental screening starting at age 7 years, the time recommended by the American Association of Orthodontists [24] or at least by the age of $8-8.5$ years, the expected time for achieving the early mixed dentition,

(c) documentation by the pediatrician, during the child's regular medical screening, of mouth breathing and sucking habits, followed by referral for treatment of these habits. The prevalence/severity of certain aspects of malocclusion (posterior crossbite, irregularity index) would be decreased, oral health improved, awareness raised and potentially the screening protocol modified in pediatric residency. 
4.3.2. Long-Term Recommendations. Current dental insurance schemes are limited in Lebanon particularly for orthodontic treatment. Affordable access to orthodontic care is facilitated by the presence of 4 postgraduate orthodontic programs in the Beirut area. In other countries, oral healthcare is provided through private dental insurance and poorly to moderately funded public programs. In Europe, particularly Scandinavian countries characterized by their universal healthcare coverage, severe malocclusion is treated free of charge until a certain age (usually 18 years) and at low cost thereafter [49].

Such schemes might not be cost effective in Lebanon before studies and pilot programs help weigh the viability of any insurance plan before implementation. Focus on prevention may be more effective in the initial phases. Interceptive orthodontic treatment in US Medicaid patients has been effective in reducing malocclusion severity; some subjects might not require additional comprehensive orthodontic treatment at later stages $[50,51]$.

4.4. Research Considerations. A number of parents of children in private schools refused to enlist their children in the study because they had their own dentist. The lower percentage of private school respondents possibly impacted the rate and severity of malocclusion between the school groups. The study did not include children from the more expensive private schools, presumably representing higher living standards and different lifestyles, thus possibly altering some findings with potentially more divergence between both types of schools investigated.

Self-reporting might have affected the accuracy or underestimated some variables because of recall bias or misinterpretation of the question. Both limitations might have been diminished or overcome if the investigators had a direct interview with the parents.

Long-term follow-up on the screened subjects should confirm the reported associations and explore new ones among the studied parameters.

\section{Conclusions}

Malocclusion was more severe in preadolescent school children from lower socioeconomic background, indicating social disparities in oral health. Some associations were found between malocclusion and societal/behavioral parameters (e.g., sucking habits, prevalent in public school children, with open bite and posterior crossbite; crowding among mandibular incisors with DMFT score [indicative of oral hygiene]). Except for a lower prevalence of overjet/overbite in private schools, Lebanese school children have more severe malocclusion components than American children.

\section{Conflict of Interests}

The authors declare that there is no conflict of interests regarding the publication of this paper.

\section{References}

[1] J. Kelly and C. Harvey, An Assessment of the Teeth of Youths 1217 Years, DHEW Pub No. (HRA) 77-1644, National Center for Health Statistics, Washington, DC, USA, 1977.

[2] W. R. Proffit, H. W. Fields Jr., and L. J. Moray, "Prevalence of malocclusion and orthodontic treatment need in the United States: estimates from the NHANES III survey," The International Journal of Adult Orthodontics \& Orthognathic Surgery, vol. 13, no. 2, pp. 97-106, 1998.

[3] B. W. Bresnahan, H. Asuman Kiyak, S. H. Masters, S. P. McGorray, A. Lincoln, and G. King, "Quality of life and economic burdens of malocclusion in U.S. patients enrolled in Medicaid," The Journal of the American Dental Association, vol. 141, no. 10, pp. 1202-1212, 2010.

[4] A.-M. Bollen, "Effects of malocclusions and orthodontics on periodontal health: evidence from a systematic review," Journal of Dental Education, vol. 72, no. 8, pp. 912-918, 2008.

[5] A. Bjork, A. Krebs, and B. Solow, "A method of epidemiological registration of malocclusion," Acta Odontologica Scandinavica, vol. 22, pp. 27-41, 1964.

[6] R. Grabowski, F. Stahl, M. Gaebel, and G. Kundt, "Relationship between occlusal findings and orofacial myofunctional status in primary and mixed dentition: part I: prevalence of Malocclusions," Journal of Orofacial Orthopedics, vol. 68, no. 1, pp. 26-37, 2007.

[7] F. Stahl and R. Grabowski, "Orthodontic findings in the deciduous and early mixed dentition-inferences for a preventive strategy," Journal of Orofacial Orthopedics, vol. 64, no. 6, pp. 401416, 2003.

[8] F. J. Robke, "Effects of nursing bottle misuse on oral health: prevalence of caries, tooth malalignments and malocclusions in North-German preschool children," Journal of Orofacial Orthopedics, vol. 69, pp. 5-19, 2008.

[9] V. Dhar, A. Jain, T. E. van Dyke, and A. Kohli, "Prevalence of gingival diseases, malocclusion and fluorosis in school-going children of rural areas in Udaipur district," Journal of Indian Society of Pedodontics and Preventive Dentistry, vol. 25, no. 2, pp. 103-105, 2007.

[10] D. S. Rwakatema, P. M. Ng'ang'a, and A. M. Kemoli, "Prevalence of malocclusion among 12-15-year-olds in Moshi, Tanzania, using Bjork's criteria," East African Medical Journal, vol. 83, no. 7, pp. 372-379, 2006.

[11] J. Varrela, "Early developmental traits in Class II malocclusion," Acta Odontologica Scandinavica, vol. 56, no. 6, pp. 375-377, 1998.

[12] M. R. de Almeida, A. L. P. Pereira, R. R. de Almeida, R. R. de Almeida-Pedrin, and O. G. D. S. Filho, "Prevalence of malocclusion in children aged 7 to 12 years," Dental Press Journal of Orthodontics, vol. 16, no. 4, pp. 123-131, 2011.

[13] R. A. de Souza, M. B. B. D. A. Magnani, D. F. Nour, F. L. Romano, and M. R. Passos, "Prevalence of malocclusion in a Brazilian schoolchildren population and its relationship with early tooth loss," Brazilian Journal of Oral Sciences, vol. 7, no. 25, pp. 15661570, 2008.

[14] Z. A. Murshid, H. E. Amin, and A. M. Al-Nowaiser, "Distribution of certain types of occlusal anomalies among Saudi Arabian adolescents in Jeddah city," Community Dental Health, vol. 27, no. 4, pp. 238-241, 2010.

[15] F. Behbehani, J. Årtun, B. Al-Jame, and H. Kerosuo, "Prevalence and severity of malocclusion in adolescent Kuwaitis," Medical Principles and Practice, vol. 14, no. 6, pp. 390-395, 2005. 
[16] E. S. J. Abu Alhaija, K. S. Al-Nimri, and S. N. Al-Khateeb, "Orthodontic treatment need and demand in 12-14-yearold north Jordanian school children," European Journal of Orthodontics, vol. 26, no. 3, pp. 261-263, 2004.

[17] A. Kassis, J. Bou Serhal, and N. Bassil Nassif, "Malocclusion in Lebanese orthodontic patients: an epidemiologic and analytic study," International Arab Journal of Dentistry, vol. 1, pp. 35-43, 2010.

[18] F. K. Saleh, "Prevalence of malocclusion in a sample of Lebanese schoolchildren: an epidemiological study," Eastern Mediterranean Health Journal, vol. 5, no. 2, pp. 337-343, 1999.

[19] A. A. Doğan, E. Sari, E. Uskun, and A. M. Şahin Sağlam, "Comparison of orthodontic treatment need by professionals and parents with different socio-demographic characteristics," European Journal of Orthodontics, vol. 32, no. 6, pp. 672-676, 2010.

[20] M. Mtaya, P. Brudvik, and A. N. Åstrøm, "Prevalence of malocclusion and its relationship with socio-demographic factors, dental caries, and oral hygiene in 12- to 14-year-old Tanzanian schoolchildren," European Journal of Orthodontics, vol. 31, no. 5, pp. 467-476, 2009.

[21] D. Gratrix and P. J. Holloway, "Factors of deprivation associated with dental caries in young children," Community Dental Health, vol. 11, no. 2, pp. 66-70, 1994.

[22] B. Melsen and S. Terp, "The influence of extractions caries cause on the development of malocclusion and need for orthodontic treatment," Swedish Dental Journal, vol. 15, pp. 163-169, 1982.

[23] P. Frazão and P. Capel Narvai, "Socio-environmental factors associated with dental occlusion in adolescents," American Journal of Orthodontics and Dentofacial Orthopedics, vol. 129, no. 6, pp. 809-816, 2006.

[24] American Association of Orthodontists, Good Dental Health Starts Early 2011, American Association of Orthodontists, St. Louis, Mo, USA, 2012, https://www.aaoinfo.org/.

[25] T. W. Beck, "The importance of a priori sample size estimation in strength and conditioning research," Journal of Strength and Conditioning Research, vol. 27, no. 8, pp. 2323-2337, 2013.

[26] World Health Organization, Oral Health Surveys: Basic Methods, World Health Organization, Geneva, Switzerland, 4th edition, 1997, http://apps.who.int/iris/.

[27] S. Zupančič, M. Pohar, F. Farčnik, and M. Ovsenik, "Overjet as a predictor of sagittal skeletal relationships," European Journal of Orthodontics, vol. 30, no. 3, pp. 269-273, 2008.

[28] P. M. Sinclair and R. M. Little, "Maturation of untreated normal occlusions," American Journal of Orthodontics, vol. 83, no. 2, pp. 114-123, 1983.

[29] S. E. Bishara, J. E. Treder, and J. R. Jakobsen, "Facial and dental changes in adulthood," American Journal of Orthodontics and Dentofacial Orthopedics, vol. 106, no. 2, pp. 175-186, 1994.

[30] L. Perillo, M. Esposito, A. Caprioglio, S. Attanasio, A. C. Santini, and M. Carotenuto, "Orthodontic treatment need for adolescents in the Campania region: the malocclusion impact on self-concept," Patient Preference and Adherence, vol. 8, pp. 353-359, 2014.

[31] S. H. D. C. S. Peres, S. Goya, K. L. Cortellazzi, G. M. B. Ambrosano, M. D. C. Meneghim, and A. C. Pereira, "Self-perception and malocclusion and their relation to oral appearance and function," Ciencia e Saude Coletiva, vol. 16, no. 10, pp. 40594066, 2011.

[32] H. A. Kiyak, "Does orthodontic treatment affect patients' quality of life?" Journal of Dental Education, vol. 72, no. 8, pp. 886-894, 2008.
[33] A. W. Tung and H. A. Kiyak, "Psychological influences on the timing of orthodontic treatment," American Journal of Orthodontics and Dentofacial Orthopedics, vol. 113, no. 1, pp. 2939, 1998.

[34] B. Q. Souki, G. B. Pimenta, M. Q. Souki, L. P. Franco, H. M. G. Becker, and J. A. Pinto, "Prevalence of malocclusion among mouth breathing children: do expectations meet reality?" International Journal of Pediatric Otorhinolaryngology, vol. 73, no. 5, pp. 767-773, 2009.

[35] G. K. Stookey, "The effect of saliva on dental caries," Journal of the American Dental Association, vol. 139, no. 5, pp. 11-17, 2008.

[36] Y. Liu, Z. Li, and M. P. Walker, "Social disparities in dentition status among American adults," International Dental Journal, vol. 64, no. 1, pp. 52-57, 2014.

[37] R. A. van Norman, "Digit-sucking: a review of the literature, clinical observations and treatment recommendations," The International Journal of Orofacial Myology, vol. 23, pp. 14-34, 1997.

[38] R. Bachir and M. Chaaya, "Maternal smoking: determinants and associated morbidity in two areas in Lebanon," Maternal and Child Health Journal, vol. 12, no. 3, pp. 298-307, 2008.

[39] M. Chaaya, J. Awwad, O. M. R. Campbell, A. Sibai, and A. Kaddour, "Demographic and psychosocial profile of smoking among pregnant women in Lebanon: public health implications," Maternal and Child Health Journal, vol. 7, no. 3, pp. 179186, 2003.

[40] E. Larsson, "Sucking, chewing, and feeding habits and the development of crossbite: a longitudinal study of girls from birth to 3 years of age," Angle Orthodontist, vol. 71, no. 2, pp. 116-119, 2001.

[41] J. J. Warren and S. E. Bishara, "Duration of nutritive and nonnutritive sucking behaviors and their effects on the dental arches in the primary dentition," The American Journal of Orthodontics and Dentofacial Orthopedics, vol. 121, no. 4, pp. 347-356, 2002.

[42] P. Cozza, T. Baccetti, L. Franchi, M. Mucedero, and A. Polimeni, "Sucking habits and facial hyperdivergency as risk factors for anterior open bite in the mixed dentition," American Journal of Orthodontics and Dentofacial Orthopedics, vol. 128, no. 4, pp. 517-519, 2005.

[43] S. Melink, M. V. Vagner, I. Hocevar-Boltezar, and M. Ovsenik, "Posterior crossbite in the deciduous dentition period, its relation with sucking habits, irregular orofacial functions, and otolaryngological findings," American Journal of Orthodontics and Dentofacial Orthopedics, vol. 138, no. 1, pp. 32-40, 2010.

[44] L. Szyszka-Sommerfeld and J. Buczkowska-Radlińska, "Influence of tooth crowding on the prevalence of dental caries. A literature review," Annales Academiae Medicae Stetinensis, vol. 56, no. 2, pp. 85-88, 2010.

[45] J. Buczkowska-Radlinska, L. Szyszka-Sommerfeld, and K. Wozniak, "Anterior tooth crowding and prevalence of dental caries in children in Szczecin, Poland," Community Dental Health, vol. 29, no. 2, pp. 168-172, 2012.

[46] B. Solow and L. Sonnesen, "Head posture and malocclusions," European Journal of Orthodontics, vol. 20, no. 6, pp. 685-693, 1998.

[47] O. Fukuta, R. L. Braham, K. Yokoi, and K. Kurosu, "Damage to the primary dentition resulting from thumb and finger (digit) sucking," Journal of Dentistry for Children, vol. 63, no. 6, pp. 403-407, 1996.

[48] S. M. Adair, M. Milano, and J. C. Dushku, "Evaluation of the effects of orthodontic pacifiers on the primary dentitions 
of 24- to 59-month-old children: preliminary study," Pediatric Dentistry, vol. 14, no. 1, pp. 13-18, 1992.

[49] E. Capilouto, "The dentist's role in access to dental care by Medicaid recipients," Journal of Dental Education, vol. 52, no. 11, pp. 647-652, 1988.

[50] D. L. Patrick, R. S. Y. Lee, M. Nucci, D. Grembowski, C. Z. Jolles, and P. Milgrom, "Reducing oral health disparities: a focus on social and cultural determinants," BMC Oral Health, vol. 6, article S4, 2006.

[51] G. King, C. Spiekerman, G. Greenlee, and G. Huang, "Randomized clinical trial of interceptive and comprehensive orthodontics," Journal of Dental Research, vol. 91, no. 7, supplement, pp. 59S-64S, 2012. 


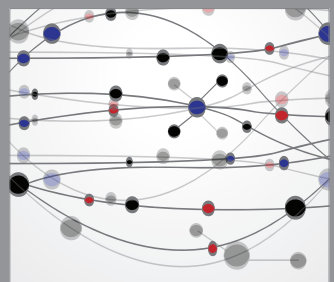

The Scientific World Journal
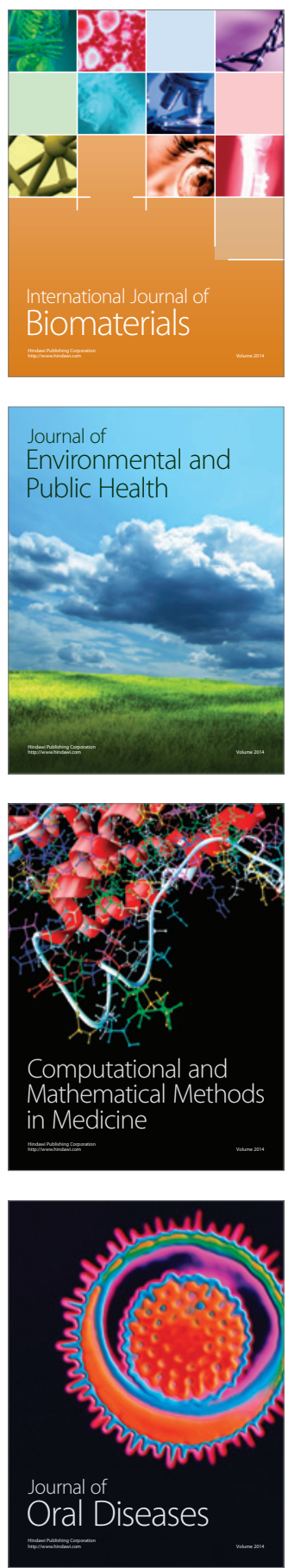
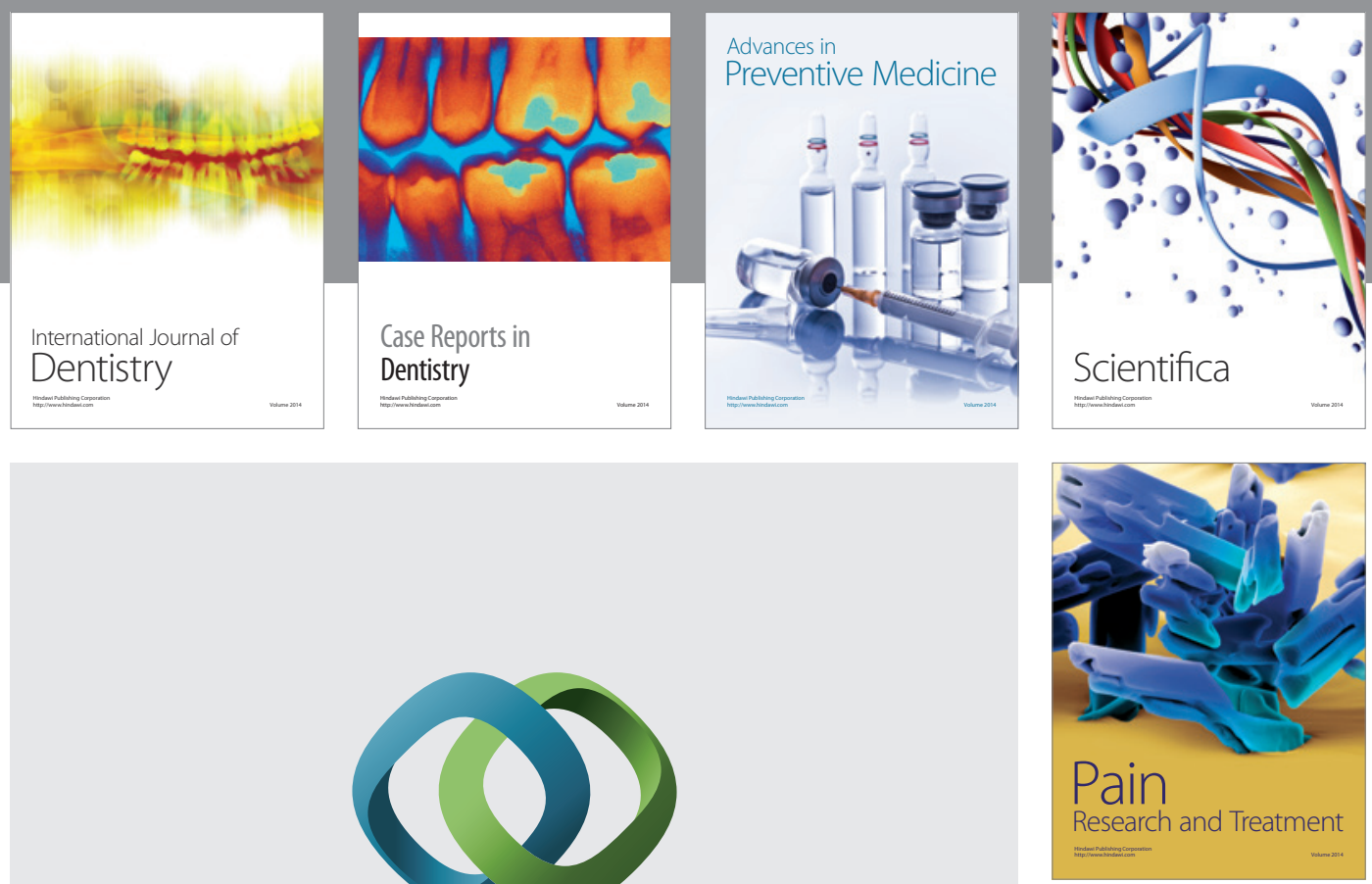

\section{Hindawi}

Submit your manuscripts at

http://www.hindawi.com
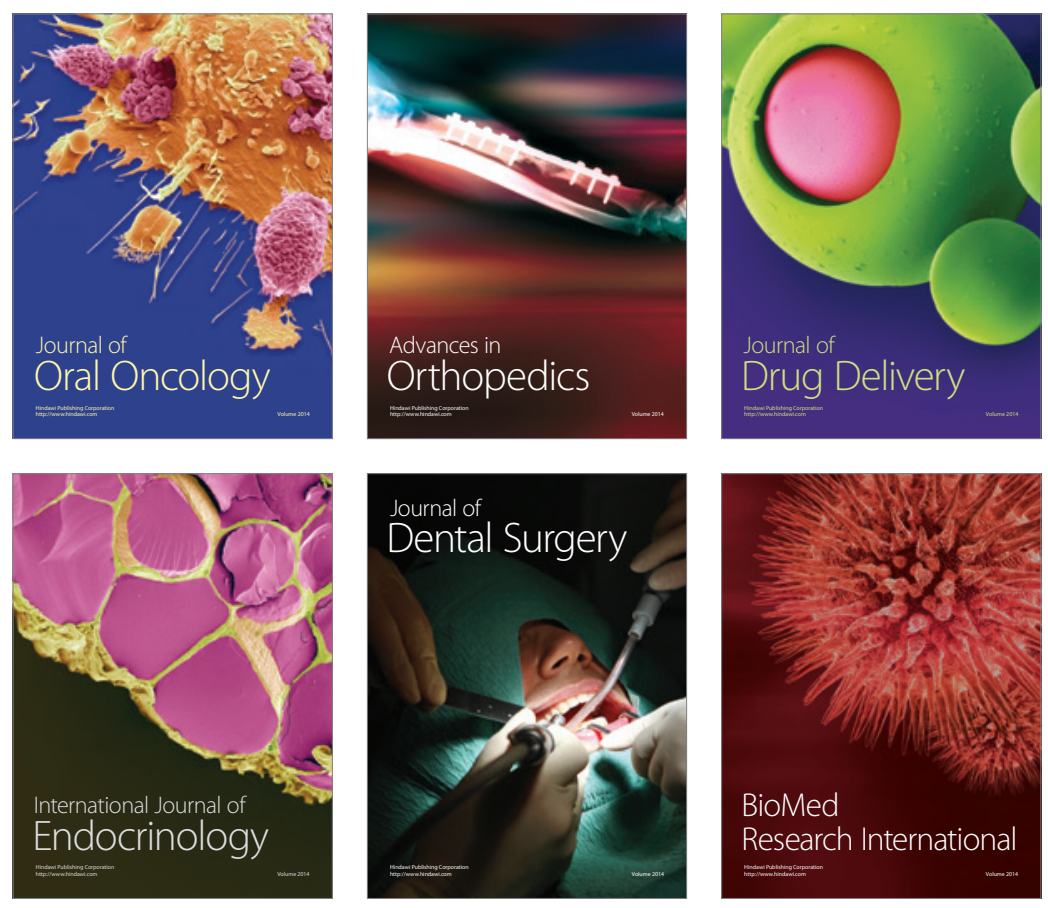

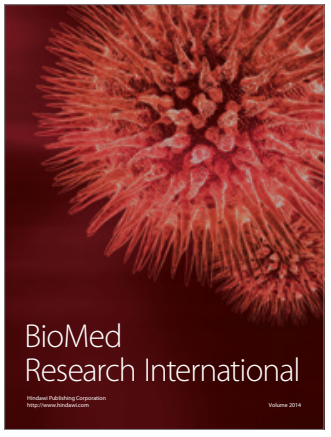

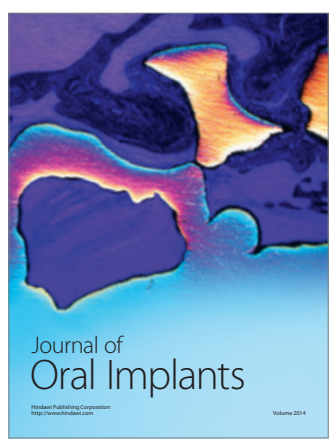
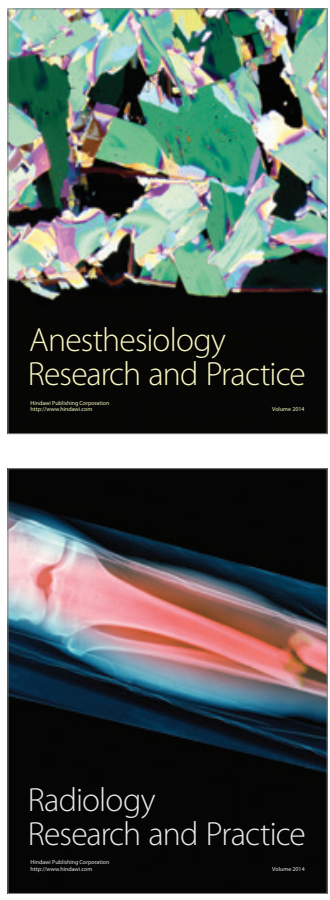